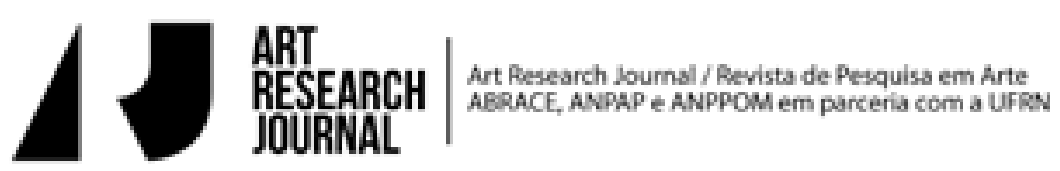

\section{Visões cinematográficas da ópera nos trópicos ${ }^{1}$}

Paulo M. Kühl

Universidade Estadual de Campinas, Brasil pmkuhl@gmail.com

O objetivo é discutir duas visões específicas sobre ópera nos trópicos, aqui entendidos como um lugar distante, relativamente misterioso e, no mais das vezes, problemático. Trata-se certamente de uma construção de fora, realizada em centros que olham para os trópicos como periferia. O cinema, ao construir uma poderosa combinação de imagens, sons e sensações, serve aqui como uma das mais significativas possibilidades para abordar o tema, uma vez que ajuda a cristalizar e a divulgar determinadas concepções, quase que naturalizando-as e conferindo-Ihes um caráter de verdade permanente. Para tratar de alguns aspectos do problema, proponho o exame de dois filmes muito distintos, que, de algum modo, apresentam vários dos paradigmas mais usuais quando se pensa em ópera "nos trópicos". São eles: Orphée Noir (Marcel Camus, 1959) e Fitzcarraldo (Werner Herzog, 1982). Os dois filmes têm propostas muito distintas, sendo o mais recente uma narrativa em que a ópera está presente como o motor da ação e como um dos elementos essenciais da trama; o mais antigo, uma espécie de transposição de uma possível "ópera tropicalizada" para o cinema. Contudo, apesar das diferenças, podemos reconhecer em ambos uma ênfase na oposição entre natureza e civilização, entre campo e cidade, entre elementos locais e estrangeiros (nos temas, na música, nos grupos étnicos, entre outros). Certamente, o cinema traz uma combinação de sons e imagens e de ação e narrativa que são muito diferentes de uma ópera encenada. ${ }^{2}$ Levando em conta tais elementos, é possível examinar como o cinema constrói, através desses dois exemplos, duas visões muito particulares sobre as possibilidades de migração da ópera da Europa para outros cantos do mundo.

\footnotetext{
1 Uma versão preliminar deste artigo foi apresentada na 1st Transnational Opera Studies Conference, Universidade de Bolonha, 29 de junho a 02 de julho de 2015; a viagem contou com financiamento da FAPESP (Proc. n. 2015/08134-1).

2 Os estudos sobre ópera e cinema têm crescido nos últimos tempos, mas neste trabalho a abordagem é diferente daquela utilizada por autores como Citron (2000 e 2010), Grover-Friedlander (2005) e os ensaios editados por Joe e R. Theresa (2002).
} 
Se pensarmos no início do período em que a corte portuguesa veio ao Brasil, encontraremos algumas indicações de interesse para esta discussão. Dentro do mundo da ópera, temos uma significativa citação de um jornal carioca em língua francesa sobre a oposição entre natureza e civilização:

Enquanto a música de Rossini encanta, no Teatro Imperial, uma briIhante sociedade de espectadores reunidos em uma sala decorada com todos os ornamentos da mais rica arquitetura, índios, reunidos em uma floresta na mesma latitude, a algumas vintenas de léguas da capital civilizada do império, despedaçam os membros do viajante perdido, ao som discordante de um chifre de boi que lhes serve de trompete. ${ }^{3}$ (L'Écho de L'Amérique du Sud, 3 out. 1827).

Vê-se aqui de maneira clara uma concepção que opõe a ópera de tradição europeia, representada aqui por Rossini, seu expoente máximo no período, àquilo que parece mais primitivo - o canibalismo acompanhado por uma música "bárbara". Trata-se de um contraste amplificado, justamente com o objetivo de mostrar as contradições percebidas por um estrangeiro na cidade do Rio de Janeiro. Em outro viajante, Ludwig von Rango, a visão é mais radical, já que "tudo o que a natureza faz por este país é magnificente, por isso parece tanto mais pobre o que o homem criou"4. Nesta visão, diante da natureza esplendorosa, todas as realizações humanas sempre parecerão pequenas, não restando alternativas para quem quiser dedicar-se às artes.

Se lembrarmos do projeto de instalação da Academia de Belas-Artes no Rio de Janeiro a partir de 1816, poderemos compreender que de fato se acreditava na possibilidade de transferir modelos culturais europeus para o país, o que fica evidente no plano que Joachim Le Breton elaborou para o seu funcionamento (Barata, 1959). Não se trata de um projeto ingênuo, mas, sim, do fruto de uma longa experiência do autor na organização do ensino artístico, no envolvimento com instituições ligadas ao mundo das artes e na confiança, herdada da Idéologie, de que as sociedades podiam encontrar os meios necessários para resolver seus

\footnotetext{
3 "Tandis que la musique de Rossini enchante au Théâtre Impérial une brillante société de spectateurs rassemblés dans une salle décorée avec tous les ornements de la plus riche architecture, des Indiens, réunis dans une forêt placée sous la même latitude, à quelques vingtaines de lieues de la capitale civilisée de l'empire, dépècent les membres du voyageur égaré, au son discordant d'une corne de bœuf qui leur sert de trompette" (L'Echo de L'Amérique du Sud, 3 de outubro de 1827).

${ }^{4}$ Carta de 21/12/1819 (Leithold; Rango, 1966, p. 144). No original: "Alles, was die Natur für dies Land gethan hat, ist vollendet schön, aber desto erbärmlicher erscheint jedes von Menschen Erschaffene" (Rango, 1832, p. 131).
} 
problemas através de uma racionalização de suas estruturas. Le Breton, pelo que se conhece, não tinha um projeto específico para os assuntos utilizados nas artes produzidas no Brasil; já um de seu conterrâneo, Ferdinand Denis, fez uma espécie de recomendação aos escritores brasileiros, particularmente conhecida pela atenção que Ihe foi dada por Antonio Candido em sua Formação da Literatura Brasileira de 1959:

Se esta parte da América adotou uma linguagem aperfeiçoada pela nossa velha Europa, ela deve rejeitar as ideias mitológicas devidas às fábulas da Grécia; usadas por nossa longa civilização, elas foram trazidas para praias onde as nações não as podiam bem compreender, onde elas deveriam sempre permanecer desconhecidas; elas não estão em harmonia, não estão de acordo nem com o clima, nem com as tradições. A América, brilhante de juventude, deve ter pensamentos novos e enérgicos como ela $[\ldots]^{5}$. (Denis, 1826, $\mathrm{p}$. 515-516).

Explicita-se aqui a relação entre uma linguagem importada e aperfeiçoada e os temas locais, mostrando uma crença na universalidade da linguagem. Vemos então uma oscilação nas posições: da total inviabilidade da inserção da cultura europeia no país, passando pela possibilidade de adaptação, contanto que se usem os temas locais, até a plena transposição de modelos artísticos - seriam assim vários os possíveis caminhos para resolver a tensão entre tradições locais e estrangeiras. O movimento indianista, o romantismo e o modernismo, com o movimento antropofágico, seriam respostas a essas questões colocadas desde a abertura do Brasil aos estrangeiros. Ao examinarmos os dois filmes, entendo ser possível neles reconhecer alguns paradigmas reproduzidos constantemente, pois o cinema consegue criar imagens que trazem muitos significados e que ajudam a consolidar determinadas visões, neste caso, sobre as possibilidades de transferência cultural da Europa para o Brasil, especialmente naquilo que se relaciona aos espetáculos teatrais com música.

\section{Fitzcarraldo}

O filme de Werner Herzog funciona na presente argumentação como a explicita-

\footnotetext{
5 "Si cette partie de l'Amérique a adopté un langage qu'a perfectionné notre vieille Europe, elle doit rejeter les idées mythologiques dues aux fables de la Grèce: usées par notre longue civilisation, elles ont été portées sur des rivages où les nations ne pouvaient bien les comprendre, où elles auraient dû toujours être méconnues; elles ne sont en harmonie; elles ne sont d'accord ni avec le climat, ni avec la nature, ni avec les traditions. L'Amérique, brillante de jeunesse, doit avoir des pensées neuves et énergiques comme elle [...]" (Denis, 1826, p. 515-516).
} 
ção de um importante modelo mais tradicional de pensamento, segundo o qual a transferência da cultura europeia - no caso, a ópera - é representada como um sonho quase impossível e que envolve uma tarefa hercúlea e, talvez, inglória ${ }^{6}$. Note-se que transferir aqui significa uma grande empreitada: erigir um teatro com a acústica adequada, com as tradições próprias de uma casa de ópera da época (edifício imponente, um foyer de circulação, salas, fosso de orquestra etc.), além da importação de cantores solistas e do coro, de instrumentos e instrumentistas, e assim por diante. Se de um lado, no início do filme, vemos no Teatro Amazonas, em Manaus, a apresentação de Enrico Caruso e Sarah Bernhardt como um exemplo concreto dessa transferência, ao mesmo tempo, o filme enfatiza uma série de contradições: o público "local", ou seja, mestiço, é mantido do lado de fora do teatro; o porteiro do teatro (representado por Milton Nascimento) é negro e também está excluído da representação7; é apenas o dinheiro da borracha, fonte da riqueza dos barões, que possibilita a inserção da cultura europeia na selva, e tal processo já é mostrado como algo desmesurado e inadequado.

O sonho do personagem Fitzcarraldo é construir uma casa de ópera em Iquitos, no Peru, e levar Caruso para lá cantar. Sem o apoio dos barões locais, o estranho herói consegue terras na floresta para explorar a borracha e fazer o dinheiro necessário para construir seu teatro. Para tanto, porém, deverá passar por cima de um morro entre dois rios, enfrentar indígenas hostis e resolver uma série de problemas de ordem prática. A floresta é representada como um obstáculo intransponível, até mesmo indiferente às investidas do processo civilizatório, mostrado em toda sua violência. No filme, vários pequenos elementos enfatizam as numerosas contradições envolvidas: os ricos são apenas ricos, desperdiçam dinheiro, não apreciam a boa música, frequentam bordéis e não têm nenhum projeto como o de Fitzcarraldo; os nativos, quase sempre descamisados ( $\mathrm{e}$, portanto, excluídos de um dos elementos essenciais da cultura - as vestimentas), não parecem ter iniciativa própria e, de certo modo, apenas obedecem às ordens com alguma ma-

\footnotetext{
${ }^{6}$ Não quero dizer que Herzog seja um representante desse tipo de pensamento, mas, sim, que ele cristaliza, de maneira crítica, essa visão em seu filme, o que nos leva a refletir sobre o assunto.

7 Não deixa de ser tentador interpretar a presença de Milton Nascimento no filme como uma reação "local" à presença de Caruso. Deixando a veracidade cronológica de lado, é como se ao Caruso italiano fosse possível responder com um Caruso brasileiro. No filme, a fala do porteiro, quando se dirige a Molly (Claudia Cardinale) e Fitzcarraldo (Klaus Kinski), é: "Eu também queria estar lá dentro".
} 
nemolência. Dom Aquilino, personagem representado por José Lewgoy, insiste que "não é fácil civilizar os índios". O significado da fala poderia ser estendido a todo o conjunto que se apresenta diante do personagem: não é fácil civilizar os trópicos. Os indígenas, quando começam a expedição na floresta, não aparecem e ouvemse apenas os famigerados tambores, que funcionam como um alerta da ameaça iminente, mas invisível. Segundo o capitão holandês, a selva engana os sentidos, é cheia de mentiras, demônios e ilusões, e qualquer tentativa de "progresso", como, por exemplo, um trecho de ferrovia (onde aparece Grande Otello em um papel mínimo), é mostrada em ruínas, devorada pela mata. Na verdade, vê-se apenas um trecho de ferrovia, uma tentativa de ingresso na floresta densa, que logo se mostra impossível. A fumaça negra que sai da embarcação surge sempre como uma representação concreta da violência à natureza, a qual, por sua vez, é exibida de maneira hostil. Trata-se, assim, de um embate incessante, no qual toda proposta de "melhoramento" fracassará. Se olharmos para o conjunto da produção de Herzog, tanto Aguirre, a cólera dos deuses (1972) como Cobra verde (1987, baseado no livro $O$ vice-rei de Uidah, de Bruce Chatwin) já inseriam seus protagonistas numa impossível relação entre o mundo europeu e o mundo tropical (africano ou sul-americano). Nos dois casos, o encontro com o outro leva à completa destruição dos dois heróis. Como lembra Lutz Koepnick (1993), ao comentar Fitzcarraldo e Aguirre, os filmes trazem a representação do herói ocidental incapaz de deixar seu imaginário europeu no confronto com o desconhecido e daí vem sua necessária e incontornável derrocada.

A música, em vários níveis, tem um papel essencial em Fitzcarraldo ${ }^{8}$. Quando os tambores parecem ameaçar o navio, a reação do protagonista é levar o gramofone para o topo da embarcação e responder com a voz de Caruso, independentemente das palavras que estão sendo cantadas. Assim, a voz - ou a música pura, já que os indígenas não compreenderiam nada do que estava sendo dito - teria o poder de silenciar os bárbaros e, talvez, de conquistá-los, um pouco à maneira de Orfeu comovendo as feras. Do modo como foi construída pelo diretor, a imagem tornase uma referência inesquecível: diante da grandiosidade da natureza insubmissa, a voz de Caruso é a única forma de competição possível. Ele já havia usado, sem sucesso, o mesmo artifício com os barões da borracha e com as crianças. Assim,

8 Para um exame pormenorizado do uso da música no filme, veja-se Lepert (2007). 
apenas no embate entre a música dos bárbaros e a música europeia, parece haver uma vitória da civilização. Um pouco mais adiante no filme, depois de a tripulação ter desertado, Fitzcarraldo mais uma vez apela para a música, dizendo que "agora realmente precisamos de ópera italiana". Aqui, assim como no relativo final feliz do filme (com a sugestiva apresentação da ária de Arturo, A te, o cara, amor talora, do primeiro ato de I Puritani de Bellini no navio), a música tem um papel restaurador e, sobretudo, redentor. Diante de toda a série de impossibilidades, da incompreensão geral das duas partes (índios e europeus), a música europeia, que se apresenta como universal, é capaz de conquistar os ouvidos e os ânimos dos "bárbaros". Claro, trata-se de uma relação pessoal do personagem Fitzcarraldo com a ópera: sua paixão pela música é tão desmesurada que, ao mesmo tempo, ela é causa de todos os seus infortúnios e também o único remédio possível para eles. Dentro de sua loucura, nem a paisagem, nem a natureza, nem as pessoas têm alguma importância para ele; apenas a música interessa e pode redimi-lo.

Contudo, neste caso específico, o recurso do final feliz musical assemelha-se mais a um deus ex machina do que propriamente a uma convicção plena dos personagens e do diretor do filme. Em Burden of Dreams, documentário de autoria de Les Blank sobre a realização de Fitzcarraldo, percebe-se uma curiosa e perversa semelhança entre o projeto do personagem Fitzcarraldo e o do próprio Herzog - é como se o filme Fitzcarraldo fosse uma autobiografia do diretor. Este teve de esperar quase quatro anos para ver seu filme pronto e enfrentou uma série de dificuldades financeiras, políticas, estratégicas, de engenharia etc. até conseguir realizar sua obra, em certa medida semelhantes àquelas por que passou o protagonista do filme. Ao final do documentário, justamente no momento em que muitos dos problemas estavam a ponto de inviabilizar seu projeto, Herzog faz um desabafo em depoimento a Les Blank:

É um lugar inacabado. É pré-histórico. A única coisa que falta aqui são os dinossauros. É como uma maldição que recai sobre toda a paisagem. E quem quer que entre demasiadamente nisso carrega uma parcela dessa maldição. Assim estamos amaldiçoados pelo que fazemos aqui. É uma terra que deus, se ele existe, criou com raiva. É a única terra em que a criação ainda está inacabada. Olhando de perto o que está a nossa volta, há uma espécie de harmonia. É a harmonia do assassinato esmagador e coletivo. E nós, em comparação com a vileza e a baixeza e a obscenidade de toda essa selva; em comparação com toda essa enorme articulação, nós parecemos e soamos como frases mal pronunciadas e semiacabadas, retiradas de 
um conto suburbano estúpido - um conto barato. ${ }^{9}$ (Herzog, 1982, $1: 20: 07-1: 24: 06)$.

Herzog, de algum modo, também cai numa armadilha ao tentar domesticar a floresta durante a produção do filme e parece incapaz de reconhecer outras maneiras de se relacionar com a natureza, que Ihe é apenas hostil ("pré-histórica", "inacabada", "obscena"). Cria-se assim uma descontinuidade - intransponível - entre a cultura ocidental representada pela ópera e pelo cinema, e a floresta, que, mais uma vez, fica relegada à posição do outro absoluto. Desse modo, é apenas através da violência que a cultura europeia pode impor-se em terras bárbaras e, na verdade, com resultados duvidosos. Se pensarmos em algumas frases que aparecem no filme, tais como "a conquista do inútil" e o "espetáculo da floresta"10, ou o próprio "peso dos sonhos", entende-se a grande empreitada civilizatória como uma quimera sem sentido.

São vários e recorrentes os exemplos que reforçam a ideia do conflito entre civilização e natureza. É possível recordar aqui um ensaio de Aldous Huxley de 1929, "Woodsworth in the Tropics", no qual o autor critica uma visão romântica da natureza, apontando sobretudo as grandes contradições envolvidas na experiência diante daquilo que é percebido como hostil. Algumas passagens do ensaio são explícitas na tentativa de combater Woodsworth e seus seguidores: ao dizer que as concepções do poeta são válidas para a latitude de cinquenta graus, o autor afirma que, nos trópicos, não seria possível experimentar os mesmos sentimentos:

A floresta é maravilhosa, fantástica, bela; mas também é aterradora, profundamente sinistra. Há algo, por falta de palavra melhor, que precisamos chamar do caráter das grandes florestas [...] que é estrangeiro, apavorante, fundamental e completamente inimigo do homem intruso. A vida daquelas vastas massas de vegetação abundante é estranha ao espírito humano e hostil a ele. (Huxley, 1929, p. 114).

\footnotetext{
9 "It's an unfinished country. It's still pre-historical. The only thing that is lacking is the dinosaurs here. It's like a curse weighing on an entire landscape. And whoever goes too deep into this has his share of that curse. So we are cursed with what we are doing here. It's a land that God, if he exists, has created in anger. It's the only land where creation is unfinished yet. Taking a close look at what's around us there is some sort of a harmony. It is the harmony of overwhelming and collective murder. And we in comparison to the articulate vileness and baseness and obscenity of all this jungle; uh, we in comparison to that enormous articulation we only sound and look like badly pronounced and half-finished sentences out of a stupid suburban novel - a cheap novel" (Herzog [em depoimento a Les Blank], 1982, 1:20:07 - 1:24:06).

${ }^{10}$ Aliás, a conquista do inútil é também o título que Herzog escolheu para suas reflexões sobre o filme (Herzog, 2010).
} 
Claro é que a concepção de Huxley a respeito da natureza e do papel do homem dentro dela é mais complexa do que o trecho pode indicar; o autor insiste mais no estranhamento como experiência fundamental em relação à natureza, tal como nos lembra Schmithausen (2001), e em textos posteriores amplia sua visão sobre o papel do homem dentro de uma natureza atacada pela civilização. De qualquer modo, podemos igualmente evocar a experiência concreta de Fordlândia, malfadado projeto implantado por Henry Ford na Amazônia, também ele com uma série de contradições e, sobretudo, impregnado da ideia de domesticar a natureza indomável (Grandin, 2009). Mas é sempre importante lembrar que a oposição aqui é entre civilização (europeia ou norte-americana) e natureza; não entre cultura europeia/norte-americana e, no caso, cultura amazônica. Mais uma vez, é necessário dizer que certamente Werner Herzog não é um europeu colonialista reproduzindo preconceitos. Ao contrário, seu filme explicita as variadas dificuldades do contato entre mundos demasiado díspares; além disso, o documentário de Les Blank traz ainda mais elementos para alimentar a discussão. Contudo, em Fitzcarraldo configura-se um dos paradigmas constantemente associados à colonização, que já se havia explicitado desde os escritos de Humboldt e que também era visível em comentários de outros viajantes que passaram pelo Brasil, sedimentando um tipo de visão muito clara a respeito da dificuldade em conhecer e dominar aquilo que é apresentado como o mundo dos trópicos.

\section{Orfeu do carnaval (Orphée noir)}

Outro modelo possível, assumido pelos escritores românticos brasileiros, diz respeito ao uso de temas locais como alternativa àqueles europeus. Resta, sem dúvida, a pergunta se a linguagem (a língua, a música, a pintura, a escultura, o cinema etc.) seria universal e, portanto, independente da matéria a ser tratada. Sartre (1948), no prefácio à antologia de poesia negra, procurou mostrar como a língua do colonizador francês transforma-se em um instrumento possível de expressão local e também de resistência. De qualquer modo, a onda indianista do século XIX pode ser lida nesse contexto; mas podemos igualmente pensar em um momento posterior, de adaptação e atualização de mitos europeus, o que pode ser visto no outro filme, o Orfeu no carnaval de Marcel Camus. O tema de Orfeu e de seu amor eterno por Eurídice não apenas está presente na tradição ocidental, mas também é parte essencial do surgimento dos espetáculos inteiramente musicados, vistos em 
geral como uma grande novidade e como uma "invenção" própria do século XVII. Por sua associação à música e à poesia e a seus poderes combinados, Orfeu está no fundamento da ópera e também nas várias tentativas de "reformas" desse tipo de espetáculo. Indicando a associação íntima entre poesia e música, e também seu poder de redenção, a presença de Orfeu serviu em vários momentos da história para criar, adaptar e renovar espetáculos inteiramente musicados.

Criar um Orfeu abrasileirado (no caso, negro, na favela do Rio de Janeiro) com música, para o cinema, é um projeto ambicioso. Conhece-se um exemplo anterior de uma adaptação brasileira do mito de Orfeu, do século XIX, para o teatro: tratase do Orfeu na roça, com texto de Correa Vasques ${ }^{11}$, uma paródia do Orfeu nos infernos (1858) de J. Offenbach, originalmente com libreto de Halévy e Crémiaux. É uma farsa da farsa, uma vez que a obra de Offenbach já era uma derivação do tema original de Orfeu. De qualquer modo, o Orfeu na roça é uma versão "tropical" do tema, o que pode ser depreendido já no título e também na lista de personagens, com nomes como Zeferino Rabeca (Orfeu), Joaquim Preguiça (Morfeu), D. Deolinda (Vênus) etc. ${ }^{12}$

A tentativa de adaptação aqui se dá pela crítica satírica, o que já existia na versão francesa, mas desta vez insistindo em elementos locais, que enfatizam as contradições entre o mito original e aquele em terras tropicais. Em certa medida, expõe-se o ridículo da tentativa, uma vez que, ao assumir novas configurações, o mito transforma-se completamente, perdendo a seriedade original. Seria essa a única via possível? Procópio Ferreira, que realizou um estudo sobre Vasques com a intenção de defender o uso das comédias, o que talvez não seja mais necessário hoje em dia, ao tratar das dificuldades do teatro no Brasil, escreveu: "Lembremonos de que arte é efeito, não é causa. Nasce espontaneamente e se desenvolve segundo as condições ambientes. É absolutamente fruto da terra: - não se impõe, nem se transplanta" (Ferreira, 1979, p. 13). Na metáfora natural, associada a uma visão determinista, salta aos olhos a ideia de que a transferência, com ou sem violência, não seria possível.

\footnotetext{
${ }^{11}$ A peça está transcrita em Ferreira (1979, p. 166-210). O autor também escreveu uma continuação, Orfeu na cidade, publicada em 1870.

${ }^{12}$ Aqui não é o momento para uma discussão prolongada sobre o tema, que já foi trabalhado por outros autores: na própria introdução do livro de Procópio Ferreira; Souza (2006); Yon (2014); Levin (2014) e Fléchet (2014).
} 
Já o filme de Marcel Camus insere-se em outra tradição e tem múltiplas referências, que vão desde o já mencionado prefácio de Sartre (1948) ao número Orphée noir da Présence Africaine até, de maneira mais específica, o Orfeu da Conceição, de Vinicius de Moraes, parcialmente musicado por Tom Jobim e estreado no Theatro Municipal do Rio de Janeiro em $1956^{13}$. A peça de Vinicius oscila entre a proposta de "helenização" do morro, inspirada na leitura de Orfeo ed Euridice de Ranieri de' Calzabigi, e a de atualizar o mito. Neste caso, tal helenização é mais uma faceta da adaptação: agora são tomados os modelos europeus que, entendidos como universais, podem ser reconhecidos inclusive no morro carioca. Na nota explicativa que acompanha a edição da peça (Moraes, 1986, p. 400), o autor indica que "todas as personagens devem ser normalmente representadas por atores da raça negra" e também insiste no uso da gíria popular que, por ser mutável, deve sempre ser atualizada. Assim se garantiria uma aproximação de dois universos distantes no tempo e no espaço - a Grécia mítica e o mundo carioca. Já a transposição para o filme traz uma série de mudanças, não aprovadas por Vinicius, utilizando apenas algumas das ideias originais do autor. De qualquer modo, o filme conseguiu criar uma poderosa combinação de imagens e música, que, naquele momento, atraiu um gigantesco público fora do Brasil, vencendo a Palma de Ouro do Festival de Cannes e o Oscar de melhor filme estrangeiro. São várias as polêmicas que envolveram a realização e a produção do filme, além de uma série de desavenças entre os autores brasileiros e os franceses, com diversas implicações para a compreensão dos seus múltiplos significados. Contudo, seu sucesso ajudou a criar uma imagem importante do Brasil, de sua gente, de seus costumes e de sua música, ainda que equivocada segundo critérios de autenticidade.

Tudo no filme apela para um exotismo de grande apelo para o público internacional: as pessoas dançam praticamente o tempo todo - claro, é carnaval, mas a presença da música, especialmente a parte de percussão, em quase toda a duração do filme cria uma sensação de constante trepidação -, quase todos os personagens são negros, vestidos de maneira muito colorida, e parecem levar uma vida alegre em meio à pobreza. A maior parte da ação acontece no morro, com a deslumbrante paisagem do Rio de Janeiro ao fundo. Em alguns momentos, surge a cidade construída, em oposição ao morro: o Palácio Capanema (marco da arqui-

13 É longa e cheia de meandros a história da escrita do Orfeu de Vinicius de Moraes e a posterior adaptação para o cinema. Veja-se Stam (1997, p. 166-178). 
tetura moderna no país) ou edifícios da Cinelândia (Theatro Municipal, Biblioteca Nacional), ou ainda a Assembleia Legislativa. Há outras vistas da cidade construída e cria-se uma oposição entre o morro e a cidade europeizada ("eclética" ou moderna). É justamente no espaço não europeu e, consequentemente, não branco que se constrói o lugar de um povo quase "naturalmente" musical: todos cantam ${ }^{14} \mathrm{e}$ dançam o tempo todo e é ali que se vai desenvolver a história de amor entre Orfeu e Eurídice, com seu final funesto. A tragicomédia pastoral, que está na gênese da ópera, é transmutada em um drama negro na favela. É como se, por oposição a um mundo branco civilizado em plena decadência e desconectado de qualquer raiz, surgisse um mundo negro mais autêntico e sensual, justamente o único lugar possível para a existência de uma nova tragédia com música. $O$ apelo que o filme teve fora do Brasil está provavelmente ligado a isso, criando e reforçando estereótipos que foram criticados no Brasil e no exterior, desde Jean-Luc Godard até Barack Obama ${ }^{15}$.

A música traz uma combinação de um samba mais tradicional (samba-canção, samba-enredo), de músicas de carnaval (inclusive do frevo), de pontos de umbanda e da recém-surgida bossa nova ${ }^{16}$. Alguns autores notam que, de um ponto de vista histórico mais rigoroso, a bossa nova não havia subido o morro em 1959 e, consequentemente, não poderia ser o principal meio de expressão de seus moradores. É curioso pensar, dos filmes que retratam o Brasil, que são sempre construções artísticas, que se exige um rigor raramente exigido de uma ópera. Assim, há um conjunto de vários tipos de música brasileira representados no filme, mas, de certo modo, é um vago espírito sedutor de carnaval que é apresentado como alternativa "tropical" e negra ao modelo tradicional europeu de ações com música. Trata-se, talvez, de mais uma idealização do que seria o autêntico, também repetida até mesmo por aqueles que buscam uma visão crítica da transferência da cultura europeia para as várias partes do mundo. Robert Stam, que apontou diversas contradições do filme com relação a questões de raça e gênero, afirma:

Mas, no fim das contas, o encanto do Orfeu negro deriva da energia pulsante do próprio carnaval, em sua combinação de uma incom-

\footnotetext{
${ }_{14}$ Vale notar que, dentre os animais que vivem no barraco de Orfeu, existe um galo que se chama Caruso.

${ }^{15}$ Para detalhes sobre a recepção crítica do filme, veja-se Fléchet (2009).

${ }^{16}$ Sobre o uso da música no filme, com suas diversas contradições, inclusive de natureza política, veja-se Grasse (2004).
} 
parável força percussiva com uma intensa beleza lírica. A beleza do filme está no que Metz chamaria de elementos "pró-fílmicos": o carnaval que virtualmente se encenou diante das câmeras de Marcel Camus. Como uma das mais gigantescas expressões da criatividade popular no mundo, o carnaval é uma verdadeira ópera popular [folk opera], mesclando as várias artes tais como a música, a narrativa, a dança, a poesia e o vestuário. A imagem do Brasil de Camus é a do carnaval tropical, onde o pulso da vida se expressa nos tambores, com o ritmo predominando sobre a trilha sonora, levando os atores a uma dança que para sempre se forma e se dissolve e se forma novamente. (Stam, 1997, p. 176-177).

Note-se, mais uma vez, a associação entre os tambores e aquilo que se torna típico dos trópicos. O problema aqui é comparar o carnaval à ópera, ou várias outras manifestações "populares", como a festa do boi, a procissão do Círio de Nazaré etc. Continua-se a repetir uma visão que toma como modelo a ópera europeia; assim, o carnaval e outras festas populares são tão artísticas quanto a ópera e, por isso, têm sua qualidade resguardada, pelo menos para uma visão tradicional. A medida continua sendo a ópera (provavelmente de matriz italiana), e a "boa arte" será a que mais se aproxima dela.

A ópera, como espetáculo híbrido, custa a encontrar discursos que deem conta de sua complexidade. Entre a música, o libreto e o espetáculo como um todo são várias as abordagens possíveis, mas, em um primeiro momento, a musicologia mais tradicional ocupou-se sobretudo dos aspectos composicionais. Ao mesmo tempo, o estudo da ópera no Brasil assumiu para si preocupações nacionalistas e, consequentemente, despontou um desconforto muito grande com um gênero visto como italiano por excelência e que teria dificuldades de ser encarado como brasileiro. Apesar de parecer um jogo de palavras, há ainda certos ecos do problema: tratase de ópera brasileira ou de ópera italiana feita no Brasil? Além disso, desde o início do século XIX, a presença da ópera, de seus teatros, do repertório, das pessoas envolvidas na produção, foi vista de maneira ambivalente: ou como um marco de civilização ou como a importação de um gênero dramático-musical demasiado caro e estranho às necessidades do país. Os nacionalismos dos séculos XIX e XX e 0 movimento de criação de óperas nacionais na década de 1850 sempre apontaram a dicotomia que envolve um espetáculo estrangeiro em busca de uma raiz autóctone. A equação nunca é facilmente resolvida e constantemente se apela para a nacionalidade dos envolvidos, para os temas dos libretos ou para características específicas da composição musical como forma de solucionar o problema - o que, 
aliás, não é exclusivo da música ou da ópera, mas faz parte de um conflito mais amplo que envolve as várias esferas da vida cultural, social, econômica e política. Em geral, parece haver uma sensação permanente de inviabilidade de uma plena instalação de um projeto operístico nacional, como se houvesse uma incompatibilidade intrínseca entre as tradições da ópera italiana (ou francesa) e as condições culturais e sociais do país. Ao mesmo tempo, as respostas "nacionais" parecem cair na armadilha de um exotismo sedutor, sem se dar conta do público para que foram concebidas. Roberto Schwarz abre seu conhecido ensaio "Nacional por subtração" lembrando que "brasileiros e latino-americanos fazemos constantemente a experiência do caráter postiço, inautêntico, imitado da vida cultural que levamos" (Schwarz, 1987, p. 29). No ensaio, a discussão toma muitos rumos, mas o autor insiste no caráter equivocado de certos problemas causados pelo paradigma de modelo-cópia.

Tal paradigma também está presente, em certa medida, em discursos estrangeiros sobre a ópera no Brasil, pelo menos naqueles mais antigos. A curiosidade sobre o que acontecia em termos de ópera no país estava mais ligada à verificação da expansão do repertório do que propriamente a estudos que buscassem compreender os vários aspectos e significados da presença da ópera nas cidades brasileiras, reproduzindo uma visão de centro e periferia. É apenas em estudos dos últimos 20 ou 30 anos que houve uma ruptura de tal modelo com um interesse mais amplo sobre a vida musical em sentido mais abrangente e, certamente, as propostas de uma história global da música ou de uma abordagem transnacional puderam ampliar a visão sobre a ópera. Contudo, parece-me que os paradigmas tão bem explicitados nos dois filmes discutidos ainda estão presentes: seja na dificuldade de a ópera/civilização implantar-se nos trópicos, seja na vontade de encontrar uma resposta autóctone ao modelo europeu.

\section{Considerações finais}

Ao olharmos para os dois filmes que, de alguma forma, funcionam como emblemas de modos de pensar os problemas relacionados à transferência cultural, não se pretende resolver as complexidades envolvidas no assunto. O que mais me interessa, pensando especificamente no caso da ópera, não é propor uma alternativa para a composição de óperas no Brasil, mas refletir sobre alguns paradigmas, tão bem expressos nos filmes que ainda estão presentes no modo como se estu- 
da a história da ópera. Mesmo depois de tantas transformações nas abordagens, ainda existem resquícios de preconceitos que são tomados como verdades, e não como construções de um tipo específico de pensamento e que precisam ser reconsiderados para podermos ampliar as possibilidades de estudo da ópera.

O primeiro deles, talvez ainda o mais arraigado e persistente, diz respeito à música como linguagem universal. Se Haydn afirmava que sua música podia ser compreendida em todo o mundo ${ }^{17}$ - o que foi usado para tornar o classicismo vienense um modelo universal -, hoje em dia estudos de antropologia mostram que não se pode mais pensar assim. E, se de fato a música é universal, deveríamos ouvir o que os diversos grupos étnicos espalhados pelo mundo teriam a dizer sobre a música "ocidental". É, aliás, o que propõe Sally Price (2002) no caso das artes visuais. Se nós possuímos os instrumentos para olhar a arte de todos os povos, já que se trataria de uma linguagem universal, deveríamos conhecer o que outros povos pensam sobre a arte "ocidental" nos museus. O mesmo deve valer sobre a música; se de fato acreditamos numa linguagem musical universal, todos têm algo a dizer sobre suas mais variadas manifestações no espaço e no tempo. Contudo, os discursos sobre a música (ou sobre as artes em geral) organizam-se segundo tradições específicas, com abordagens históricas, estético-filosóficas, antropológicas, pertencentes às tradições das disciplinas acadêmicas. É desejável, ou mesmo possível, incluir os variados discursos? Voltando ao livro de Sally Price, a autora mostra como, mesmo em casos em que parece haver poucas informações, é possível identificar autores, traçar genealogias artísticas, encontrar relações. O mesmo vale para os estudos sobre ópera e música, mesmo com outros critérios: por exemplo, ao estudar-se a difusão de um dado repertório, é possível ver as novas mediações que o reconstroem, dando-Ihe novos e muitas vezes insuspeitos significados. Um caso exemplar é o das modinhas e lundus aproveitando trechos de ópera (Ulhôa; Costa Lima Neto, 2013).

No caso específico do estudo de óperas, mas não só nele, notamos uma diferença substancial, por exemplo, nas reações que a ópera despertou, praticamente desde seu surgimento no início do século XVII, no mundo teórico europeu. Por razões diversas, se olharmos para o Brasil do século XVIII, quando chegam os primeiros espetáculos de ópera, notamos um relativo silêncio do mundo da crítica, que nos

${ }_{17}$ Segundo o conhecido relato de A. C. Dies (1810, p. 75). 
leva a duas hipóteses complementares: o mundo da teoria não estava interessado na ópera; a ópera cumpria plenamente todos os seus papéis na sociedade e não despertaria nenhuma questão. Isso já foi visto como uma espécie de "minoridade crítica" por alguns autores, padrão que também é repetido no estudo da produção artística em geral: numa terra "pré-histórica", resistente à cultura, germinam apenas frutos deformados e distorcidos do padrão europeu. Além disso, há uma desproporção na quantidade de documentos disponíveis para o estudo da ópera no Brasil, se comparada, por exemplo, à Itália ou à França. Deveriam ser os mesmos métodos e os mesmos procedimentos de pesquisa utilizados mundo afora? Talvez a atuação do historiador da ópera no Brasil seja mais próxima da de um arqueólogo, que conta com fragmentos para elaborar a compreensão de seus temas de pesquisa.

Há também mais um problema, que seria o da "carnavalização" total da produção artística no Brasil. Na ausência de um aparato conceitual mais apropriado, tomam-se o "carnaval", o "barroco", o "sensual", "o tropical" e o "sincrético", entre outros, como modelos essencializados para os estudos sobre a cultura e a produção artística no país. Com isso, confere-se um lugar marginal para essa produção e também para os estudos que dela tratam. Sem dúvida alguma, há importantes exceções, mas em geral se pensa o estudo da ópera italiana no Brasil como um capítulo demasiado distante do estudo central da ópera italiana (entendida aqui como ópera em língua italiana). Novamente é o exotismo a atrair a atenção: ópera italiana no meio da selva - o que isso pode significar? Talvez seria a ópera nos confins do mundo civilizado mais um item para um gabinete de curiosidades, ou para um filme com um personagem quixotesco.

Por fim, ainda há um tema um tanto difícil. Existe ou existia a expectativa, justamente por se constituir como um outro, de que aquilo que vem dos longínquos trópicos traga algum tipo de autenticidade, ou pelo menos uma coerência que se ligue a uma resistência à cultura europeia. Um pouco como se os primitivos devessem permanecer primitivos e seguir uma história independente do contato com o europeu. É um mito de pureza como compensação a tanta barbárie criada pela cultura ocidental. Novamente se trata de uma questão muito mais complexa de intercâmbio, ainda que assimétrico, entre as culturas. Gostaria de fazer referência a uma pintura, Imortalidade, de Branco e Silva (Figura 1), com a representação do Teatro Amazonas em Manaus, e onde estão explicitadas muitas contradições: de um lado, 
o próprio teatro, envolto por uma nuvem de musas que passam pelo edifício e ascendem aos céus; mais à esquerda, uma queda d'água de um rio caudaloso, provavelmente uma referência à força das águas amazônicas (estranhamente semeIhante à foz do rio Iguaçu); por fim, em primeiro plano, um conjunto de amazonas guerreiras, algumas montadas em seus cavalos, nuas, portando armas, olhando em direção ao teatro. Trata-se de uma relação entre três forças claras: a natureza, a civilização europeia e os indígenas. Contudo, aqui, é necessário lembrar que as amazonas são figuras míticas, narradas por Heródoto, Estrabão e Apolônio de Rodes, entre outros. Como se sabe, foi no século XVI que o termo foi empregado para descrever mulheres guerreiras na América do Sul e, posteriormente, o nome passou ao rio, à região e a um estado brasileiro. É curioso pensar que as figuras míticas, que vieram da Europa e que foram de certo modo abrasileiradas, olhem com certo espanto para o teatro, que também veio de uma outra Europa. Isso nos dá uma dimensão, ainda que através de uma pintura "menor", das várias camadas que se foram sedimentando no país, certamente através da violência e do uso da força, nas imagens que temos de diferentes culturas - o que constrói um paradoxo constante para quem se interessa pelo mundo das artes e de sua história no país.

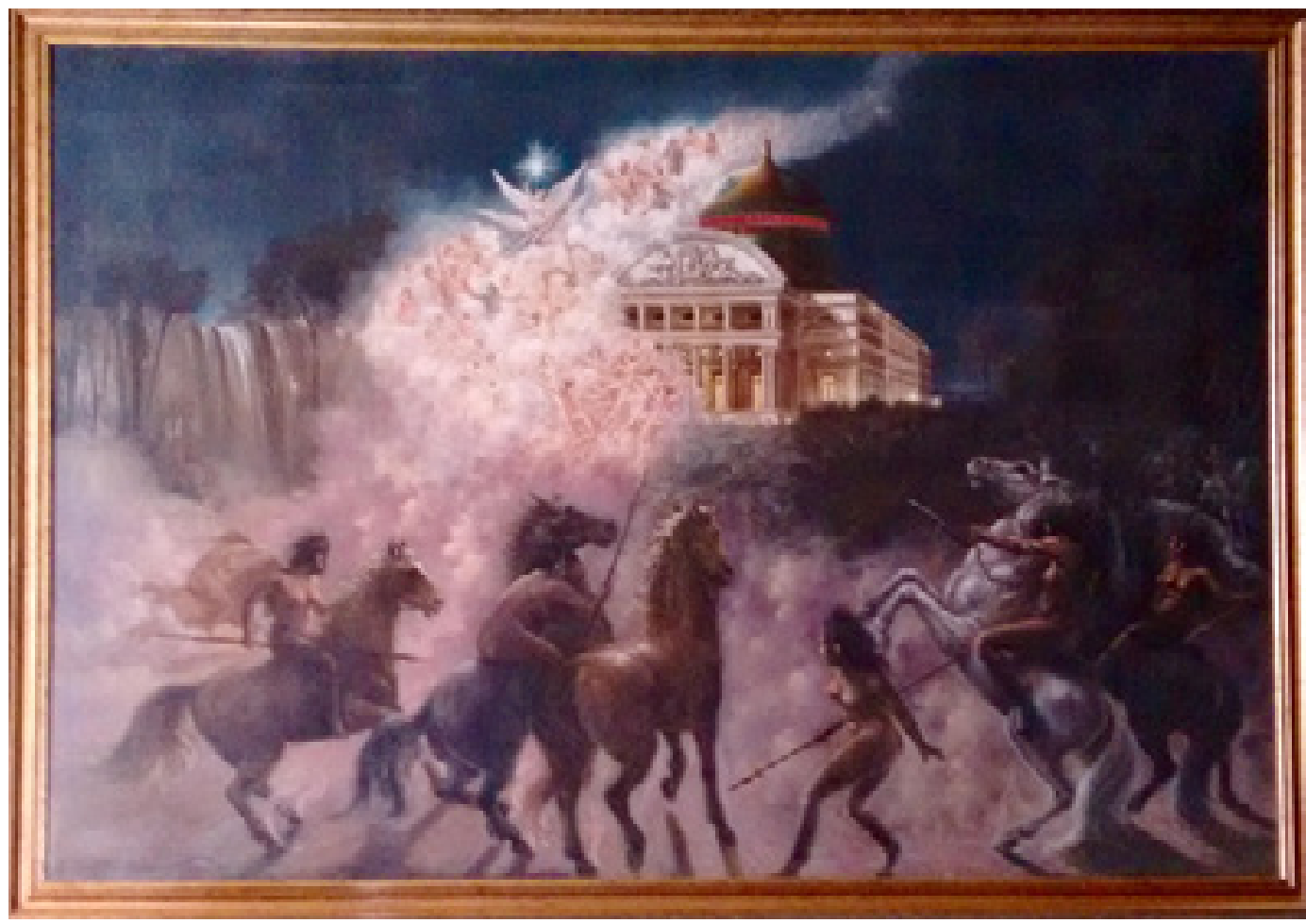

Figura 1. Branco e Silva. Imortalidade.

1940. Óleo sobre tela, 2,60 m x 1,70 m, Manaus, Palácio Rio Negro. Foto do autor. 


\section{Referências}

BARATA, Mário. Manuscrito inédito de Lebreton. Sobre o estabelecimento de dupla escola de artes no Rio de Janeiro, em 1816. Revista do SPHAN, Rio de Janeiro, n. 14 , p. 283-307, 1959.

CAMPOS-MUÑOZ, G. Contrapuntos Órficos: Mitografía brasileña y el mito de Orfeo. Latin American Research Review, v. 47, Special Issue, p. 31-48, 2012.

CITRON, Marcia J. Opera on Screen. Yale: Yale University Press, 2000.

. When Opera meets Film. Cambridge: Cambridge University Press, 2010.

CRONIN, P. (Ed.). Werner Herzog. A Guide for the Perplexed. Londres: Faber \& Faber, 2014.

DENIS, Ferdinand. Résumé de I'histoire littéraire du Portugal et du Brésil. Paris: Lecointe et Durey, 1816.

DIES, A. C. Biographische Nachrichten von Joseph Haydn. Viena: Camesina, 1810.

FERREIRA, Procópio. O ator Vasques. 2. ed. Rio de Janeiro: MEC-SEAC-FUNARTEServiço Nacional do Teatro, 1979.

FLÉCHET, Anaïs. Offenbach no Rio. A febre da opereta no Brasil do Segundo Reinado. In: ABREU, M.; DAECTO, M. M. (Eds.). A circulação transatlântica dos impressos: conexões. Campinas: IEL-Setor de Publicações, 2014. p. 311-324.

. Um mito exótico? A recepção crítica de Orfeu Negro de Marcel Camus (1959-2008). Significação, n. 32, p. 43-62, 2009.

GRANDIN, Greg. Fordlandia: The Rise and Fall of Henry Ford's Forgotten Jungle City. Nova York: Metropolitan Books; Henry Holt, 2009.

GRASSE, J. Conflation and Conflict in Brazilian Popular Music: Forty Years between 'Filming' Bossa Nova in Orfeu Negro and Rap in Orfeu. Popular Music, v. 23, n. 3, p. 291-310, oct. 2004.

GROVER-FRIEDLANDER, Michal. Vocal Apparitions: The Attraction of Cinema to Opera. Princeton, Oxford: Princeton University Press, 2005.

HERZOG, Werner. Conquest of the Useless: Reflections from the making of Fitzcarraldo. Nova York: Ecco, 2010.

HUXLEY, Aldous. Do What You Will. Londres: Chatto \& Windus, 1929.

JOE, Jeongwong; THERESA, Rose (Eds.). Between Opera and Cinema. Nova York; Londres: Routledge, 2002.

KOEPNICK, L. P. Colonial Forestry: Sylvan Politics in Werner Herzog's Aguirre and 
Fitzcarraldo. New German Critique, n. 60, Special Issue on German Film History, p. 133-159, Autumn, 1993.

LEITHOLD, Theodor von; RANGO, Ludwig von. Rio de Janeiro visto por dois prussianos em 1819. Tradução de J. de S. Leão Filho. São Paulo: Nacional, 1966.

LEPPERT, Richard. Opera, Aesthetic Violence, and the Imposition of Modernity: Fitzcarraldo. In: GOLDMARK, D.; KRAMER, L.; LEPPERT, R. (Eds.). Beyond the Soundtrack: Representing Music in Cinema. Califórnia: University of California Press, 2007. p. 99-119.

LEVIN, O. M. Offenbach e a disputa pelo público brasileiro. In: ABREU, M.; DAECTO, M. M. (Eds.). A circulação transatlântica dos impressos: conexões. Campinas: IEL-Setor de Publicações, 2014. p. 299-310.

MELBYE, D. The Contemplative Landscape. Allegories of Space in Cinema. 2006. 216 f. PhD Diss., Univ. of Southern California, 2006.

MORAES, Vinicius de. Poesia completa e Prosa. Rio de Janeiro: Nova Aguilar, 1986.

PERRONE, Charles A. Myth, Mythopeia, and Mimesis: Black Orpheus, Orfeu, and Internationalization in Brazilian Popular Music. In: PERRONE, C.; DUNN, Christopher (Eds.). Brazilian Popular Music and Globalization. Nova York; Londres: Routledge, 2002. p. 46-75.

PRAGER, Brad (Ed.). A Companion to Werner Herzog. Hoboken, NJ: Wiley-Blackwell, 2012.

PRICE, Sally. Primitive Art in Civilized Places. 2. ed. Chicago: University of Chicago Press, 2002.

RANGO, Ludwig von. Tagebuch meiner Reise nach Rio de Janeiro in Brasilien, und zurück: In den Jahren 1819 und 1820. 2. ed. Ronneburg: Friedrich Weber, 1832.

ROGERS, Holly. Fitzcarraldo's Search for Aguirre: Music and Text in the Amazonian Films of Werner Herzog. Journal of the Royal Musical Association, v. 129, n. 1, p. 77-99, 2004.

SARTRE, Jean-Paul. Orphée noir. In: SENGHOR, L. S. (Ed.). Anthologie de la nouvelle poésie nègre et malgache de la langue française. Paris: PUF, 1948. p. IX-XLIV.

SCHMITHAUSEN, Lambert. Aldous Huxley's View of Nature. In: BARFOOT, C. C. (Ed.). Aldous Huxley between East and West. Amsterdã; Nova York: Rodopi, 2001. p. 151-174.

SCHWARZ, Roberto. Nacional por subtração. In: Que horas são? - ensaios. São Paulo: Cia. das Letras, 1987.

SOUZA, Silvia C. M. de. Um Offenbach tropical. Francisco Correa Vasques e o teatro musicado no Rio de Janeiro da segunda metade do século XIX. Anais do XVIII 
Encontro Regional de História - O historiador e seu tempo, ANPUH/SP - UNESP/ Assis, 24 a 28 de julho de 2006. CD-ROM.

STAM, Robert. Tropical Multiculturalism: A Comparative History of Race in Brazilian Cinema and Culture. Durham: Duke University Press, 1997.

ULHÔA, Martha Tupinambá de; COSTA-LIMA NETO, Luiz. Memory, History and Cultural Encounters in the Atlantic: The case of Lundu. The World of Music (New Series), v. 2, n. 2, p. 47-72, 2013.

YON, J.-C. A ópera-bufa de Offenbach: algumas pistas para o estudo da circulação mundial de um repertório no século XIX. In: ABREU, M.; DAECTO, M. M. (Eds.). A circulação transatlântica dos impressos: conexões. Campinas: IEL-Setor de Publicações, 2014. p. 283-290.

\section{Filmes}

BURDEN of dreams. Direção: Les Blank. 1982.

FITZCARRALDO. Direção: Werner Herzog. São Paulo: Versátil Home Video, 1982.

ORFEU do Carnaval. Direção: Marcel Camus. São Paulo: Continental Home Video, 1959 